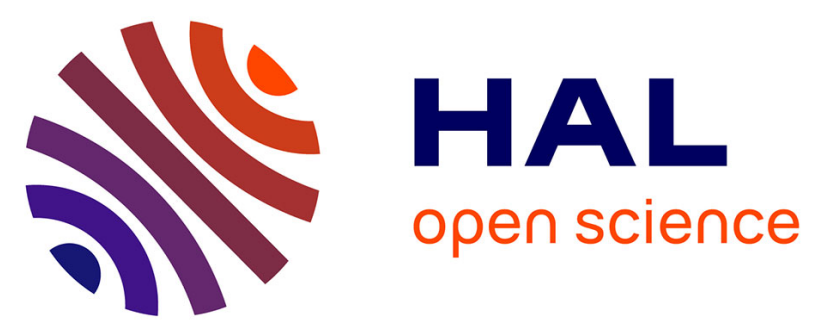

\title{
Chloroplast DnaJ-like proteins 3 and 4 (CDJ3/4) from Chlamydomonas reinhardtii contain redox-active Fe-S clusters and interact with stromal HSP70B
}

Karolin V. Dorn, Felix Willmund, Christian Schwarz, Christine Henselmann, Thomas Pohl, Barbara Hess, Daniel Veyel, Björn Usadel, Thorsten Friedrich, Jörg Nickelsen, et al.

\section{To cite this version:}

Karolin V. Dorn, Felix Willmund, Christian Schwarz, Christine Henselmann, Thomas Pohl, et al.. Chloroplast DnaJ-like proteins 3 and 4 (CDJ3/4) from Chlamydomonas reinhardtii contain redoxactive Fe-S clusters and interact with stromal HSP70B. Biochemical Journal, 2010, 427 (2), pp.205-215. 10.1042/BJ20091412 . hal-00479253

\section{HAL Id: hal-00479253 https://hal.science/hal-00479253}

Submitted on 30 Apr 2010

HAL is a multi-disciplinary open access archive for the deposit and dissemination of scientific research documents, whether they are published or not. The documents may come from teaching and research institutions in France or abroad, or from public or private research centers.
L'archive ouverte pluridisciplinaire HAL, est destinée au dépôt et à la diffusion de documents scientifiques de niveau recherche, publiés ou non, émanant des établissements d'enseignement et de recherche français ou étrangers, des laboratoires publics ou privés. 


\section{Chloroplast DnaJ-like proteins 3 and 4 (CDJ3/4) from Chlamydomonas reinhardtii contain redox-active Fe-S clusters and interact with stromal HSP70B}

Karolin V. Dorn ${ }^{*}$, Felix Willmund ${ }^{*}$, Christian Schwarz ${ }^{\dagger}$, Christine Henselmann ${ }^{*}$, Thomas Pohl ${ }^{\ddagger}$, Barbara Heß ${ }^{*}$, Daniel Veyel ${ }^{\S}$, Björn Usadel ${ }^{\S}$, Thorsten Friedrich ${ }^{\ddagger}$, Jörg Nickeisen ${ }^{\dagger}$, and Michael Schroda ${ }^{*} \S, 1$

*Institut für Biologie II, Biochemie der Pflanzen, Universität Freiburg, Schänzlestr. 1, D79104 Freiburg, Germany.

${ }^{\dagger}$ Molekulare Pflanzenwissenschaften, Biozentrum LMU München, Grosshaderner Strasse 24, Planegg-Martinsried 82152, Germany.

${ }^{\ddagger}$ Institut für Organische Chemie und Biochemie, Albert-Ludwigs-Universität Freiburg, Albertstrasse 21, Chemiehochhaus, D-79104 Freiburg i. Br., Germany.

§Max Planck Institut für Molekulare Pflanzenphysiologie, Am Mühlenberg 1, D-14476 Potsdam-Golm, Germany

${ }^{1}$ Corresponding author: Michael Schroda, Schroda@mpimp-golm.mpg.de

Page heading title: Characterization of Chloroplast DnaJ-like proteins 3-5

Key words: J-domain proteins; bacterial ferredoxin; chloroplast chaperones; redox regulation; RNA-binding proteins

Abbreviations used: HSP, heat shock protein; CDJ, chloroplast DnaJ-like protein; HEP2, Hsp70 escort protein 2; CGE1, chloroplast GrpE homolog 1; PSII, photosystem II;

Sequence data from this article have been deposited to the GenBank data library under the accession numbers GQ421467 (CDJ3) and GQ421468 (CDJ4). 


\section{SYNOPSIS}

In this study we report on the identification and characterization of three novel chloroplasttargeted J-domain proteins, CDJ3-5, which in addition to their J-domains contain bacterialtype ferredoxin domains. In the databases we could identify homologs of CDJ3-5 in green algae, moss and higher plants, but not in cyanobacteria. Phylogenetic analyses allowed distinguishing two clades containing CDJ3/4 and CDJ5 that must have diverged early in an ancestor of the green lineage and have further diversified later on Molecular and biochemical analysis of CDJ3 and CDJ4 from Chlamydomonas reinhardtii revealed that both are weakly expressed proteins that appear to be localized to the stroma and to thylakoid membranes, respectively. The low transcript levels of the CDJ3 and CDJ4 genes declined even further in the initial phase of heat shock, but $C D J 3$ transcript levels strongly increased after dark-to-light shift. Accordingly, the Arabidopsis ortholog of CDJ5 was also found to be light inducible and to be under strong circadian control. CDJ3 and CDJ4 proteins could both be expressed in Escherichia coli with redox-active Fe-S clusters. In vitro crosslinking studies demonstrated that CDJ3 and CDJ4 interact with chloroplast HSP70B in the ATP state, presumably as dimers, and immunoprecipitation studies showed that CDJ3/4 were in common complexes with HSP70B also in Chlamydomonas cell extracts. Finally, CDJ3 was found in complexes with apparent molecular masses of $\sim 550$ to $2800 \mathrm{kDa}$ that appeared to contain RNA. We speculate that CDJ3-5 might represent redox switches that act by recruiting $\mathrm{HSP} 70 \mathrm{~B}$ for the reorganization of regulatory protein complexes. 


\section{INTRODUCTION}

Molecular chaperones of the HSP70 class are highly conserved and found in all living organisms, except for some archaea. HSP70 chaperones are involved in a plethora of different cellular functions, like folding of newly synthesized proteins, refolding of denatured proteins after stress, protein quality control, transport of proteins across membranes, or assembly and disassembly of protein complexes [1]. HSP70s contain two functionally interconnected domains, an N-terminal ATPase and a C-terminal substrate-binding domain. Substrate proteins typically expose hydrophobic regions and substrate binding to HSP70 in the ATP state stimulates ATP hydrolysis [2]. This results in tight binding of the substrate when HSP70 is in the ADP state. The specificity of HSP70 function is mediated by so-called $\mathrm{J}$-domain proteins, which interact with selected substrates and deliver them to HSP70s in the ATP state [3, 4]. ATP hydrolysis is further stimulated by the interaction of the J-domain with the ATPase domain of the HSP70 partner. Exchange of ADP by ATP in most prokaryotictype HSP70s is catalyzed by GrpE-type nucleotide exchange factors [5].

Compared to the well-studied HSP70 systems in bacteria and most compartments of the eukaryotic cell (cytosol, ER, mitochondria) rather little is known about HSP70 systems in chloroplasts. This is surprising, as chloroplasts contain a compartment providing the basis for almost all life on earth - the thylakoid membranes - and knowledge about chloroplast proteostasis is mandatory to understand the biochemical mechanisms underlying the conversion of light energy into carbohydrates. To remedy this situation, we are studying the chloroplast HSP70 system in the unicellular green alga Chlamydomonas reinhardtii. Chlamydomonas possesses only one major chloroplast HSP70, termed HSP70B, and therefore is less complex than higher plants or moss containing two and three major chloroplast HSP70 homologs, respectively [6-9].

HSP70B itself is assisted by its escort protein HEP2 to assume the functional state [10]. HSP70B cooperates with its GrpE-type nucleotide exchange factor, CGE1 [11], and appears to be constitutively in complex with chloroplast HSP90C [12]. HSP70B has been shown to protect PSII from photoinhibition and to play a role in the repair of photodamaged PSII [13]. To date, two chloroplast-targeted J-domain protein co-chaperones of HSP70B have been characterized: CDJ1 in addition to the J-domain contains the Gly/Phe-rich and the Zn-finger substrate-binding domains characteristic for type I J-domain proteins [14] and therefore most likely is involved in supplying HSP70B (and HSP90C) with unfolded substrate proteins [12]. CDJ2 lacks the Gly/Phe-rich and Zn-finger domains and therefore is a type III J-domain. CDJ2 binds to the vesicle inducing protein in plastids (VIPP1) and recruits the HSP70B-HSP90C chaperone complex $[15,16]$. HSP70B, CDJ2 and CGE1 were shown to catalyze assembly and disassembly of VIPP1 oligomeric structures, and might therefore be involved in biogenesis/maintenance of thylakoid membranes [17].

Here, we report on three novel chloroplast-targeted type III J-domain proteins, termed CDJ3-5, and present a molecular and biochemical analysis of CDJ3 and CDJ4. 


\section{EXPERIMENTAL}

\section{Strains and Culture Conditions}

Chlamydomonas reinhardtii strains were grown mixotrophically in TAP medium [18] on a rotatory shaker at $25^{\circ} \mathrm{C}$ and an illumination of $\sim 30 \mu \mathrm{E} \mathrm{m} \mathrm{m}^{-1}$. For chloroplast isolation, cells were grown in TAP medium supplemented with $0.5 \%(\mathrm{w} / \mathrm{v})$ peptone.

\section{Cloning, Expression, and Purification of CDJ3 and CDJ4}

A 623-bp DNA fragment encoding the N-terminal part of mature CDJ3 was amplified by PCR

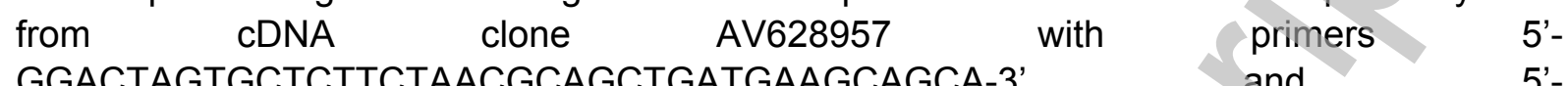
GGATTCGCGACTGCCGCCGCTGCCAGGC-3'. The PCR product was digested with Spel and cloned into Spel-Smal-digested pBluescript (Stratagene, La Jolla, CA), giving pMS330. pMS330 was digested with Spel-Ncol and the resulting 501-bp Spel-Ncol fragment was ligated into the Spel-Ncol-digested cDNA clone AV628957, giving pMS332. Next, cDNA clone AV628957 was digested with Ncol-Mfel and the resulting 894-bp Ncol-Mfel fragment was ligated into Ncol-EcoRI-digested pMS330 to generate pMS333. At last, pMS333 was digested with Sapl-Xhol and the resulting 1415-bp Sapl-Xhol fragment was cloned into SaplXhol-digested pTYB11 (NEB, Frankfurt, Germany), giving pMS336. The coding sequence for CDJ4 was amplified by PCR from CDNA clone AV643891 with primers 5'GGACTAGTGCTCTTCTAACGCAAGCAGTGATGTTGCTTC-3' 5'TACCACTCGAGAGCGGCGGAG-3'. The resulting 1006-bp PCR product was digested with Sapl-Xhol and ligated into Sapl-Xhol-digested PTYB11, generating pMS337. pMS336 and pMS337 were expressed in Escherichia coli ER2566 and purified by chitin affinity chromatography according to the manufacturer's instructions (NEB). Mature CDJ3/4 were cleaved from the intein/chitin binding domain by incubation with cleavage buffer $(20 \mathrm{mM}$ Tris/ $\mathrm{HCl}, 0.5 \mathrm{M} \mathrm{NaCl}, 1.0 \mathrm{mM}$ EDTA, $50 \mathrm{mM}$ DTT, $\mathrm{pH} \mathrm{9.0)}$ ) at $25^{\circ} \mathrm{C}$ for $16 \mathrm{~h}$ and collected in five 1-ml fractions. Fractions $1-3$ and 5 were pooled and subjected to three successive runs of concentration/dilution with $\mathrm{KMH}$ buffer (20 mM HEPES-KOH pH 7.2, $80 \mathrm{mM} \mathrm{KCl}, 2.5 \mathrm{mM}$ $\mathrm{MgCl}_{2}$ ) using Amicon Ultra-4 tubes (Millipore, Molsheim, France). Proteins were supplemented with $10 \%$ glycerol and $1 \mathrm{mM}$ DTT, frozen in liquid nitrogen, and stored at $80^{\circ} \mathrm{C}$. Yields were around $300 \mathrm{\mu g}$ pure CDJ3/4 per liter $E$. coli culture. About $1 \mathrm{mg}$ each of purified CDJ3 and CDJ4 were dissolved in $6 \mathrm{M}$ urea, $20 \mathrm{mM}$ Tris $\mathrm{pH} 8.0,0.5 \mathrm{M} \mathrm{NaCl}$ and used for the generation of polyclonal rabbit antisera. Affinity purification of antibodies was done as described previously [19].

Heat Shock and Dark-to-Light Shift Kinetics, RNA and Protein Extractions, RNA Gels, and Hybridizations

Heat-shock and dark-light-shift kinetics, isolation of protein and RNA, and preparation of RNA blots were carried out as described in [16]. Membranes were hybridized with DNA probes prepared by the random priming technique using $\left[\alpha-{ }^{32} \mathrm{P}\right] \mathrm{dCTP}$ (Hartmann Analytic $\mathrm{GmbH}$, Braunschweig, Germany). Hybridization was done as described previously [13]. Probes used were a 2-kb Nhel-Aatll fragment containing the HSP7OB coding region, the entire CDJ3 and CDJ4 cDNAs, and a 1-kb cDNA of CBLP [20]. Radioactive signals were detected with BAS-IP MS 2040 phosphorimager plates (raytest, Straubenhardt, Germany).

\section{Polyacrylamide Electrophoreses and Gel Blot Analyses}

SDS-PAGE was performed as described earlier [21]. For fractionation experiments, one volume of 2 x Laemmli sample buffer (125 mM Tris-HCl pH 6.8, 20\% glycerol, 4\% SDS, $10 \%$ 
$\beta$-mercaptoethanol, $0.005 \%$ bromphenol blue) was added to the samples and protein concentrations were determined by amido black [22]. Proteins in gels were stained with colloidal Coomassie (Invitrogen) or transferred to nitrocellulose membranes (Hybond-ECL, GE-Healthcare) by semidry blotting using a discontinuous transfer system. Blocking and immunodecorations were performed in phosphate buffered saline (containing $3 \%$ nonfat dry milk, immunodetection was done by enhanced chemiluminescence (GE-Healthcare). Antisera were against HSP70B [13], CGE1 [11], mitochondrial carbonic anhydrase [23], and cytochrome $f$ [24]. ECL signals were detected with Hyperfilm-ECL (GE-Healthcare).

\section{Cell Fractionations}

Isolation of chloroplasts and fractionation into stroma, thylakoids and low density membranes was done as described previously [25]. Mitochondria were isolated according to [26], but using a BioNebulizer ${ }^{\mathrm{TM}}$ (Glas-Col, Terre Haute, IN) for disrupting cells instead of vortexing with glass beads.

\section{Immunoprecipitations}

Chlamydomonas CF185 cells [13] were grown to a density of $-8 \times 10^{6}$ cells $/ \mathrm{mL}$, harvested in two equal fractions by centrifugation and either resuspended in $50 \mathrm{~mL}$ TAP medium prewarmed to $40^{\circ} \mathrm{C}$ for heat shock or in $50 \mathrm{~mL}$ TAP medium at $25^{\circ} \mathrm{C}$ for control. Heat shock and control treatments were performed for $1 \mathrm{~h}$ under shaking, then cells were harvested and resuspended in lysis buffer (20 mM HEPES, pH 7.2, $10 \mathrm{mM} \mathrm{KCl}, 1 \mathrm{mM} \mathrm{MgCl}, 154 \mathrm{mM} \mathrm{NaCl}$, $0.25 \times$ protease inhibitor cocktail (Roche, Mannheim, Germany)). Cells were lysed by sonication on ice. Lysates were loaded onto sucrose cushions $(20 \mathrm{mM} \mathrm{HEPES}-\mathrm{KOH} \mathrm{pH} \mathrm{7.2,}$ $0.6 \mathrm{M}$ sucrose) and centrifuged in a TI50 rotor for $30 \mathrm{~min}$ at $152,000 \mathrm{~g}$ and $4^{\circ} \mathrm{C}$. The supernatants were supplied with Triton $\mathrm{X}-100$ to a final concentration of $0.5 \%$ and incubated for $5 \mathrm{~min}$. Protein A-Sepharose beads with coupled antibodies were equilibrated in lysis buffer and incubated with the cell lysates under agitation for one $h$ at $10^{\circ} \mathrm{C}$. Beads were washed four times with lysis buffer (containing $0.1 \%$ Triton $\mathrm{X}-100$ ) and twice with $10 \mathrm{mM}$ Tris- $\mathrm{HCl}, \mathrm{pH} 7.5$, and proteins were eluted by boiling $45 \mathrm{~s}$ in $2 \times$ Laemmli sample buffer (Figure $5 \mathrm{~B}$ ), or by shaking $30 \mathrm{~min}$ at $25{ }^{\circ} \mathrm{C}$ with $2 \times$ Laemmli sample buffer lacking $\beta$ mercaptoethanol (Figure 5A).

\section{UV-vis spectroscopy}

$200 \mu \mathrm{L}$ of purified CDJ3 $(30.5 \mu \mathrm{M})$ or CDJ4 $(22.0 \mu \mathrm{M})$ in cleavage buffer were analyzed in a $1 \mathrm{~cm}$ pathlength UV micro cuvette (Brand, Wertheim) with a TIDAS-II diode array spectrophotometer (J\&M, Aalen). The samples were reduced by the addition of $5 \mu \mathrm{L} \mathrm{Na} \mathrm{N}_{2} \mathrm{~S}_{2} \mathrm{O}_{4}$ $(0.5 \mathrm{M})$ at $25^{\circ} \mathrm{C}$ and measured instantaneously. The molar extinction coefficient at $280 \mathrm{~nm}$ was calculated from the amino acid sequence according to [27] giving values of $35360 \mathrm{M}^{-}$ ${ }^{1} \mathrm{~cm}^{-1}$ for CDJ3 and $49180 \mathrm{M}^{-1} \mathrm{~cm}^{-1}$ for CDJ4, respectively.

\section{Miscellaneous}

Glutaraldehyde crosslinks were performed as described in [28] and gel filtration analysis of purified CDJ3/4 as reported in [17]. Recombinant HSP70B containing a C-terminal hexahistidine tag was coexpressed with HEP2 in E. coli and purified by Ni-NTA affinity chromatography as reported previously [10]. Stromal chloroplast proteins for size exclusion chromatography were extracted as described in [25]. For RNase treatment stromal proteins were incubated for $60 \mathrm{~min}$ at $4^{\circ} \mathrm{C}$ with $200 \mu \mathrm{g}$ of RNase A. After application of proteins to a Superose 6 column, proteins were eluted with $23 \mathrm{~cm} / \mathrm{h}(50 \mathrm{mM} \mathrm{KCl}, 5 \mathrm{mM}$-aminocaproic acid, $2.5 \mathrm{mM}$ EDTA, $20 \mathrm{mM}$ tricin/KOH pH 7.5) using an ÄKTApurifier system (GE Healthcare, Germany). Due to low abundance of CDJ3, samples were concentrated using AmiconUltra centrifugal filter devices (Millipore; USA) prior to western analysis. 


\section{RESULTS}

\section{CDJ3-5 are conserved from green alga to higher plants}

To obtain cDNAs that encode chloroplast-targeted J-domain proteins we have searched Chlamydomonas EST libraries $[29,30]$ with the amino acid sequence of the J-domain of $E$. coli DnaJ. This has led to the identification of CDJ1 and CDJ2, two chloroplast-targeted Jdomain proteins that were shown to interact with chloroplast HSP70B [12, 16]. Further, we identified two ESTs that potentially encoded additional J-domain proteins with $\mathrm{N}$-terminal extensions which by the ChloroP program [31] were predicted to be chloroplast transit peptides (Figure 1B). We termed them CDJ3 and CDJ4 (hloroplast Dna $\underline{\underline{y}}$-like proteins $\underline{3}$ and 4) and determined the full sequences of their cDNAs. The complete cDNA sequences revealed that the two proteins lacked the Gly/Phe-rich and Zn-finger domains typical for type I J-domain proteins of the DnaJ/HSP40 prototype and therefore qualified CDJ3 and CDJ4 as type III J-domain proteins [14]. Strikingly, both proteins contain a bacterial ferredoxin domain that is followed by an extended C-terminal domain of unknown function (Figure 1B). Only version 3.0 of the Chlamydomonas genome sequence [32] revealed a further gene (CDJ5) with full EST coverage that encodes another J-domain protein with a bacterial ferredoxin domain. Analysis by ChloroP qualifies the $\mathrm{N}$-terminal sequence of CDJ5 as potential chloroplast transit peptide. Unfortunately, CDJ5 was identified at a late stage of this study and therefore was not characterized in more detail. Information on molecular weights of CDJ3-5 precursors and mature proteins and similarities between their amino acid sequences is compiled in Table 1.

Database searches revealed that true homologs of CDJ3-5 existed only in green algae, moss and higher plants, each encoding at least two homologs of CDJ3-5 (note that one Ostreococcus sequence was incomplete and therefore excluded from our analysis). We wondered, whether the diversification of the CDJ3-5 family occurred early in the development of the green lineage, or rather late at the level of its different branches. Phylogenetic analysis of CDJ3-5 homologs from algae, moss, gymnosperms and angiosperms supported both hypotheses (Figure 1A): we could clearly distinguish two clades, one containing homologs of CDJ3 and CDJ4, the other containing homologs of CDJ5. The two clades must have diverged early, i.e. in the progenitor of the green lineage. But we also found diversification within the clades, e.g. in rice, which encodes at least three members of the CDJ3/4 clade.

\section{CDJ3 is inducible by light but not by heat stress}

J-domain proteins potentially support their HSP70 chaperone partner in refolding of stressdenatured proteins. Thus it was possible that the $C D J 3 / 4$ genes were heat shock-inducible. As shown in Figure 2A, the opposite was observed: both, CDJ3 and CDJ4 mRNA levels declined in response to heat shock and only started to recover when the expression of heat shock genes, e.g. HSP7OB, attenuated. Interestingly, CDJ3 mRNA levels strongly increased in cells that were shifted from a 16-h dark period to low light (Figure 2B). Here, CDJ4 mRNA levels were below the detection limit. Consistently, the mRNA level of the Arabidopsis CDJ5 ortholog atDjC17 (AT5G23240) (extracted from publicly available microarray data) increased after illumination, as well (Supplemental Figure 1). Furthermore, the mRNA levels of atDjC17 showed strong circadian cycling with a $\sim 30$ fold increase in expression towards subjective dusk [33]. This was even more marked for atDjC17 mRNA levels in plant rosettes grown under $12 \mathrm{~h} / 12 \mathrm{~h}$ light dark diurnal cycles [34]. In the case of the Arabidopsis CDJ3/4 ortholog atDjC18 (AT2G42750) weaker circadian/diurnal cycling could be observed, whereas the 
expression peaked shortly after dawn. atDjC18 was upregulated by iron starvation and both Arabidopsis genes appeared to be downregulated by sugar.

\section{CDJ3 and CDJ4 contain redox-active Fe-S clusters}

To biochemically characterize CDJ3 and CDJ4 we expressed both proteins without their predicted $\mathrm{N}$-terminal chloroplast transit peptide in $\mathrm{E}$. coli as $\mathrm{C}$-terminal fusions to the yeast VMA intein/chitin binding domain. As shown in Figure 3, the CDJ3/4 fusion proteins were well expressed in E. coli, but barely soluble. When the fusion proteins present in the soluble fraction were concentrated on the chitin columns, the columns became yellow-brownish which indicated that Fe-S clusters were already assembled into the fusion proteins. Following thiol-induced cleavage, mature CDJ3 and CDJ4 proteins with apparent molecular masses of $\sim 38$ and $\sim 34 \mathrm{kDa}$ were recovered, which corresponded well with those calculated (Table 1). Also the purified mature proteins had a yellow-brownish colour (Figure 3 ).

To assay whether CDJ3 and CDJ4 contained redox-active Fe-S clusters, we characterized the UV-vis spectroscopic properties of mature CDJ3 and CDJ4. The spectra revealed broad absorption maxima at $390 \mathrm{~nm}$ that bleached in the presence of sodium dithionite (Figure 4). Both, the oxidized and the reduced spectra are similar to those observed for $P$. aerogenes ferredoxin [35]. The extinction coefficients at $390 \mathrm{~nm}$ of the oxidized spectra and the difference extinction coefficients at $425 \mathrm{~nm}$ are in the range reported for a single [4Fe-4S] cluster [36]. It was not possible to obtain an EPR signal at various temperatures and microwave power settings, neither with the oxidized nor the reduced samples (data not shown). It is possible that the putative [4Fe-4S] clusters of CDJ3 and CDJ4 have a spin-ground state different of $S=1 / 2$. The concentration of the samples was too low to detect any contribution to the $g=4.5$ region with the $X$-band spectrometer.

\section{CDJ3 and CDJ4 interact with ATP-bound HSP70B in vitro}

As CDJ3 and CDJ4 were predicted to be targeted to the chloroplast, they were likely to interact with HSP70B, which is the major (if not the only) HSP70 in the chloroplast of Chlamydomonas [7, 8]. To test this, we performed glutaraldehyde crosslinking experiments with the purified proteins. We used HSP70B that was coexpressed with its escort protein HEP2 and therefore functional [10]. As J-domain proteins interact with their HSP70 chaperone partners in the ATP-state (see e.g. [37]), we performed crosslinks in the presence and absence of ATP. When crosslinked proteins were detected with an antiserum against HSP70B, we mainly detected HSP70B monomers (migrating slightly above the 72-kDa marker protein) and oligomers (migrating above the 170-kDa marker protein). However, we also detected crosslink products with apparent molecular masses of $\sim 140 \mathrm{kDa}$ in the lanes containing ATP, HSP70B, and CDJ3 or CDJ4 (Figure 5, left gel). These $\sim 140-k D a$ crosslink products were also detected with antisera against CDJ3 (Figure 5, middle gel) and CDJ4 (Figure 5, right gel). Hence, CDJ3 and CDJ4 appear to interact with HSP70B, but only in the ATP state. As judged from the migration of these complexes at $\sim 140 \mathrm{kDa}$ they might consist of an HSP70B monomer and a CDJ3/4 dimer. However, it is also possible that these complexes consist of monomers of HSP70B and CDJ3/4 whose migration was retarded by crosslinks that preserved higher order structures. In addition to the $\sim 140-k D a$ complex with HSP70B, only monomers of CDJ3 were detected (Figure 5, middle gel). In contrast, CDJ4 existed as monomers and two oligomeric forms, which migrated little below and little above the 72-kDa marker protein (Figure 5, right gel). Most likely, these represent CDJ4 dimers, where in the form with higher apparent molecular mass crosslinks might have preserved higher order structures. 
We could also observe oligomer formation of CDJ4 by gel filtration. As shown in Figure 6, CDJ3 and CDJ4 monomers migrated with slightly larger apparent than calculated molecular masses ( $\sim 47$ and $\sim 42 \mathrm{kDa}$ compared to $\sim 38$ and $\sim 33 \mathrm{kDa}$, respectively). While CDJ3 was only found as monomers, a small fraction of CDJ4 appeared to form oligomers. When we take into account the larger apparent molecular mass of CDJ4, the peak corresponding to a $98 \mathrm{kDa}$ oligomer rather points to a CDJ4 dimer (Figure 6).

\section{CDJ3 and CDJ4 are very weakly expressed chloroplast proteins that respectively locate to stroma and membranes}

To test, whether we could verify expression of both proteins by western analysis we used antisera that were raised against CDJ3 and CDJ4. As revealed in Figure 7, we could not, or at most barely, detect either of the two proteins in whole-cell extracts, even when we used the antisera at high concentrations. However, when we used the antisera against CDJ3 and CDJ4 to enrich the proteins by immunoprecipitation from whole-cell extracts, we could detect immunoreactive proteins with apparent molecular masses of $\sim 38$ and $\sim 34 \mathrm{kDa}$. These masses corresponded to those calculated for mature CDJ3 and CDJ4, respectively (Figure $7 A$ and Table 1). In the $\alpha$ CDJ3 and $\alpha$ CDJ4 immunoprecipitates we could also detect HSP70B. Hence, these data suggest that the CDJ3 and CDJ4 proteins are expressed at low levels in Chlamydomonas and that they may interact with HSP70B in vivo.

To verify the predicted chloroplast localization of CDJ3 and CDJ4 and to determine their suborganellar distribution, we isolated mitochondria and chloroplasts from Chlamydomonas cells. Chloroplasts were subsequently sub-fractioned into stroma, thylakoids and low-density membranes, which are considered to consist of inner envelopes and of transitory membranes between inner envelope and thylakoids [25]. The purity of the fractions was tested with antisera against mitochondrial carbonic anhydrase, stromal CGE1 and the integral thylakoid membrane protein cytochrome f. As judged from the signals obtained with these antisera (Figure 7B), chloroplasts contained mitochondrial contaminations, stroma fractions were free from thylakoid and mitochondrial contaminations, thylakoids were free from stromal contaminations, but were strongly contaminated with mitochondria, and mitochondria were pure. CDJ3 was detected in the chloroplast and stromal fractions, whereas CDJ4 was weakly detected in chloroplast and strongly detected in thylakoid fractions (Figure 7B).

\section{CDJ3 appears to be in complex with chloroplast transcripts}

As outlined in more detail in the discussion, one possible function of CDJ3-5 might be the redox-regulation of transcription/translation initiation and/or transcript stability. In this case, we expected CDJ3-5 to be associated with chloroplast transcripts. To test this hypothesis, we subjected untreated stromal extracts and extracts that have been treated with RNase to gel filtration and monitored the fractions for the presence of CDJ3. We limited our analysis to CDJ3, as we could detect it in the stroma. We also monitored gel filtration fractions for the presence of RBP40 as control, since RBP40 specifically binds to the psbD mRNA [38]. As expected, in untreated stroma RBP40 was detected in fractions with complexes ranging from $\sim 160$ to $\sim 2800 \mathrm{kDa}$, whereas in RNase-treated stroma it was shifted to fractions with complexes in the $\sim 160$ to $\sim 550 \mathrm{kDa}$ range (Figure 8). Interestingly, CDJ3 in untreated stroma was detected in fractions with complexes ranging from $\sim 550$ to $\sim 2800 \mathrm{kDa}$. RNase treatment extended the fractions in which CDJ3 was detected down to the $\sim 160 \mathrm{kDa}$ region, at the expense of material in the high molecular weight range. This suggests that part of the complexes containing CDJ3 is associated with RNA. 
To test, whether CDJ3 is binding to $p s b D$ transcripts, e.g. in association with RBP40, we isolated stromal fractions from the PRB2A mutant. In this mutant, the 7-nt long so-called PRB2 sequence in the $5^{\prime}$ UTR of the psbD mRNA is mutated, leading to destabilization specifically of the $p s b D$ transcript $[39,40]$. As shown in Figure 8, RBP40 in the PRB2A mutant was detected only in stroma fractions containing complexes in the $\sim 160$ to $\sim 660 \mathrm{kDa}$ range, corroborating the specific interaction of RBP40 with the $p s b D$ message [38]. As the distribution of CDJ3 was not altered in stroma fractions from the PRB2A mutant, CDJ3 appears to be associated with transcripts other than $p s b D$. 


\section{DISCUSSION}

We report here on the molecular and biochemical analysis of CDJ3 and CDJ4, two novel Jdomain proteins encoded by the Chlamydomonas genome. We present the following evidence that CDJ3/4 are chloroplast-targeted co-chaperones of chloroplast HSP70B: First, CDJ3/4, like all their homologs in other algae, moss and higher plants, contain $\mathrm{N}$-terminal extensions that by ChloroP/TargetP are predicted to be chloroplast transit peptides. The apparent molecular masses of mature CDJ3/4 observed in SDS-PAGE (Figure 7A) correspond to those calculated for the processed proteins (Table 1). Accordingly, fractionation experiments revealed that mature CDJ3 and CDJ4 are targeted to the chloroplast. Here they are localized to stroma and thylakoids, respectively, where also chloroplast HSP70B was localized (Figure 7B; refs. [11, 12, 15, 16, 19]). Second, HSP70B coprecipitated with both CDJ3 and CDJ4 from Chlamydomonas cell extracts (Figure 7A) and recombinant HSP70B was found to interact with recombinant CDJ3 and CDJ4 in the ATP. state in vitro (Figure 5). Third, recombinant CDJ3/4 stimulated the ATPase activity of HSP70B, albeit at a weaker extent than the bona-fide chloroplast DnaJ homolog CDJ1 (data not shown).

\section{On the evolution of ferredoxin-containing J-domain co-chaperones}

A striking feature of CDJ3 and CDJ4 is that they contain redox-active Fe-S clusters (Figures 3 and 4), which according to their spectral properties and amino acid sequences appear to be of the [4Fe-4S] type of bacterial ferredoxins (Figures 1, 3 and 4; refs [35, 36, 41]). The presence of a ferredoxin domain within a $\mathrm{J}$-domain co-chaperone is highly unusual. Accordingly, we have found genes encoding homologs of CDJ3/4 only in algae, moss, and higher plants (Figure 1). In fact, Chlamydomonas harbours a third member of this gene family that we termed CDJ5 and whose deduced amino acid sequence is more distantly related to those of CDJ3 and CDJ4 (Table 1). Each plant species analyzed encodes at least two members of the CDJ3-5 family, of which at least one belongs to the CDJ3/4 or CDJ5 subfamilies (Figure 1).

Interestingly, proteins containing both a J-domain and a bacterial ferredoxin domain are also encoded by the genomes of several members of the mesophilic Crenarchaeota (now also referred to as Thaumarchaeota) [42-44]. However, the domain architecture of the archaeal proteins differs from that of the CDJ3-5 homologs: whereas J- and ferredoxin domains are separated by a linker of 22-41 amino acids in CDJ3-5 homologs, this linker may contain up to 117 amino acids in the archaeal proteins (Figure 1B, Supplemental Figure 2). Instead of this extended linker, the CDJ3-5 homologs contain C-terminal domains of up to $\sim 300$ amino acids, which are absent in the archaeal proteins. Within their linkers, the archaeal proteins contain conserved patches of aromatic amino acids flanked by positively and negatively charged residues, which at a lower level of conservation are also found in the C-terminal domains of CDJ3-5. This might indicate that functions exerted by the archaeal linker are located to the C-terminal domains of CDJ3-5.

Genes encoding DnaK and its co-chaperones appear to be absent from the genomes of hyperthermophilic Crenarchaeota and most likely have been transferred horizontally from bacteria to mesophilic Euryarchaeota, which might have been a prerequisite for these to adapt to life at lower temperatures [44]. As to the evolution of the ferredoxin-containing Jdomain co-chaperones, three scenarios come to mind: i) the ancestor of CDJ3-5 appeared early during the evolution of the "green lineage" and was then acquired by a crenarchaeote by horizontal gene transfer. (ii) The J-domain/ferredoxin fusion occurred first in 
crenarchaeotes after they had acquired components of the bacterial DnaK system and was then transferred to an early ancestor of the "green lineage", giving rise to CDJ3-5. (iii) The Jdomain/ferredoxin fusion occurred independently in crenarchaeotes and an early ancestor of the "green lineage". Phylogenetic analyses suggest that the first scenario is the most likely one (D. Moreira and P. Lopez-Garcia, personal communication). In any case, development/maintenance of these specialized co-chaperones is likely to be the solution to a selective pressure similarly affecting mesophilic crenarchaeotes and members of the green lineage.

In fact, an Hsp70 homolog (HscA), a J-domain protein (HscB) and a Ferredoxin (Fdx) are encoded in close proximity on the bacterial isc operon and they themselves and their mitochondrial homologs Ssq1p, Jac1p, and Yah1p, respectively, are essential for Fe-S cluster biogenesis [45-47]. The HscB/Jac1p J-domain proteins facilitate the interaction of $\mathrm{HscA} / \mathrm{Ssq} 1 \mathrm{p}$ with scaffold proteins that bind Fe-S cluster intermediates. The chaperones may assist cluster formation by maintaining the scaffold proteins in a conformation suitable for cluster assembly; alternatively, they may facilitate the transfer of the cluster from the scaffold to an acceptor apoprotein [45]. The yeast mitochondrial ferredoxin homolog Yah1p was suggested to provide the reducing power for an essential step in cluster biogenesis, e.g. for cysteine reduction, iron reduction, or reduction of cluster intermediates prior to release from the scaffold proteins [47]. If the chaperones were indeed involved in the release of cluster intermediates and ferredoxin was essential for prior reduction, the integration of J-domain cochaperone and ferredoxin into the same polypeptide might have made these processes more efficient.

\section{On possible functions of CDJ3-5}

A role of the stromal HSP70 chaperone system in Fe-S cluster biogenesis might be supported by the finding that stromal HSP70s are essential [9], which is a typical feature shared by all proteins with important roles in Fe-S cluster biogenesis [48]. However, there are arguments in disfavour: first, the $\mathrm{Fdx} /$ Yah1p proteins, for which homologs in Arabidopsis and Chlamydomonas mitochondria exist [49], contain [2Fe-2S] clusters with a polypeptide fold distinct from that of [4Fe-4S] type clusters [50]. Second, if CDJ3-5 were involved in such a fundamental and conserved process like Fe-S cluster biogenesis, it would be surprising to find so many family members only in the green lineage and not in cyanobacteria or nongreen alga. Third, a possible role of CDJ3 in Fe-S cluster biogenesis is difficult to explain in light of its observed association with RNA-binding protein complexes (Figure 8).

Which functions of CDJ3-5 other than in Fe-S cluster biogenesis can we envision? We found $C D J 3$ to be strongly induced by light and the Arabidopsis ortholog of CDJ5 (atDjC17) to be light-inducible and to be under strong circadian control (Figure 2 and Supplementary Figure 1). The Fe-S clusters in CDJ3/4 are redox-active (Figure 4), both proteins interact with HSP70B (Figures 5 and 7A), and CDJ3 appears to be part of an RNAbinding protein complex (Figure 8 ). J-domain co-chaperones interact via specialized domains with specific substrate proteins and deliver them to their HSP70 partner for processing [3, 4]. Hence, it is tempting to speculate that CDJ3-5 interact with specific substrates via their Cterminal domains and that substrate binding or delivery to HSP70B occurs only at a redox state defined by their ferredoxin domains, e.g. via an internal conformational change or a reduction step. The light inducibility of CDJ3 might suggest that redox signals inflicted by light, like the oxidation state of the thioredoxin system or the accumulation of reactive oxygen species (ROS), determine the oxidation state of CDJ3-5 and, therefore, whether substrate processing by HSP70B occurs. The association of CDJ3 with RNA again might point to a chaperone-mediated remodelling of RNA-binding protein complexes that, for example, are involved in translation initiation/elongation or mRNA stability. These are found in the stroma 
and associated with thylakoids [51], where also CDJ3/4 and HSP70B are located (Figure 7B).

Well-studied examples of chaperone-mediated remodelling of replication initiation are known from E. coli, where DnaK and DnaJ monomerize RepA dimers and dissociate DnaB helicase-Lambda $\mathrm{P}$ complexes to trigger replication of plasmid $\mathrm{P} 1$ and lambda phage, respectively [52, 53]. By means of their Fe-S clusters, the transcription and translation regulators SoxR, FNR, Aconitase, and IscR sense signals like ROS, NO, cellular oxygen or iron concentrations and relay them to transcriptional or translational activities [54]. In fact, gene expression in the chloroplast is mainly regulated by nuclear-encoded factors at the level of translation initiation and/or transcript stability and, therefore, is distinct from cyanobacteria [51]. As this post-transcriptional regulation of the expression of many chloroplast genes, including $p s b A, p s b D$ and $r b c L$, is strongly regulated by light [51], we propose that CDJ3-5 might represent such nuclear-encoded factors that act as redox switches by recruiting HSP70B for the reorganization of regulatory protein complexes.

\section{ACKNOWLEDGMENTS}

We would like to thank the Kazusa DNA Research Institute for providing cDNA clones AV628957 and AV643891, encoding CDJ3 and CDJ4, respectively. We would also like to thank Francis-André Wollman for the antibody against cytochrome $f$ and Mats Eriksson for the antibody against mitochondrial carbonic anhydrase. We are grateful to P. López-García for sharing unpublished insights.

\section{FUNDING}

This work was supported by the Deutsche Forschungsgemeinschaft [Schr 617/2-4].

\section{REFERENCES}

1 Mayer, M. P. and Bukau, B. (2005) Hsp70 chaperones: cellular functions and molecular mechanism. Cell Mol Life Sci. 62, 670-684

2 Laufen, T., Mayer, M. P., Beisel, C., Klostermeier, D., Mogk, A., Reinstein, J. and Bukau, B. (1999) Mechanism of regulation of hsp70 chaperones by DnaJ cochaperones. Proc Natl Acad Sci U S A. 96, 5452-5457

3 Craig, E. A., Huang, P., Aron, R. and Andrew, A. (2006) The diverse roles of Jproteins, the obligate Hsp70 co-chaperone. Rev Physiol Biochem Pharmacol. 156, 1-21

4 Miernyk, J. A. (2001) The J-domain proteins of Arabidopsis thaliana: an unexpectedly large and diverse family of chaperones. Cell Stress Chaperones. 6, 209-218

5 Harrison, C. (2003) GrpE, a nucleotide exchange factor for DnaK. Cell Stress Chaperones. 8, 218-224

6 Rensing, S. A., Lang, D., Zimmer, A. D., Terry, A., Salamov, A., Shapiro, H., Nishiyama, T., Perroud, P. F., Lindquist, E. A., Kamisugi, Y., Tanahashi, T., Sakakibara, K., Fujita, T., Oishi, K., Shin, I. T., Kuroki, Y., Toyoda, A., Suzuki, Y., Hashimoto, S., Yamaguchi, K., Sugano, S., Kohara, Y., Fujiyama, A., Anterola, A., Aoki, S., Ashton, N., Barbazuk, W. B., Barker, E., Bennetzen, J. L., Blankenship, R., Cho, S. H., Dutcher, S. K., Estelle, M., Fawcett, J. A., Gundlach, H., Hanada, K., Heyl, A., Hicks, K. A., Hughes, J., Lohr, M., Mayer, K., Melkozernov, A., Murata, T., Nelson, D. R., Pils, B., Prigge, M., Reiss, B., Renner, T., Rombauts, S., Rushton, P. J., Sanderfoot, A., Schween, G., Shiu, S. H., 
Stueber, K., Theodoulou, F. L., Tu, H., Van de Peer, Y., Verrier, P. J., Waters, E., Wood, A., Yang, L., Cove, D., Cuming, A. C., Hasebe, M., Lucas, S., Mishler, B. D., Reski, R., Grigoriev, I. V., Quatrano, R. S. and Boore, J. L. (2008) The Physcomitrella genome reveals evolutionary insights into the conquest of land by plants. Science. 319, 64-69

7 Schroda, M. (2004) The Chlamydomonas genome reveals its secrets: chaperone genes and the potential roles of their gene products in the chloroplast. Photosynth Res. 82, 221-240

8 Schroda, M. and Vallon, O. (2008) Chaperones and Proteases. In: The Chlamydomonas Sourcebook, Second Edition. Elsevier / Academic Press

9 Su, P. H. and Li, H. M. (2008) Arabidopsis stromal 70-kD heat shock proteins are essential for plant development and important for thermotolerance of germinating seeds. Plant Physiol. 146, 1231-1241

10 Willmund, F., Hinnenberger, M., Nick, S., Schulz-Raffelt, M., Muhlhaus, T. and Schroda, M. (2008) Assistance for a chaperone: Chlamydomonas HEP2 activates plastidic HSP70B for cochaperone binding. J Biol Chem. 283, 16363-16373

11 Schroda, M., Vallon, O., Whitelegge, J. P., Beck, C. F. and Wollman, F. A. (2001) The chloroplastic GrpE homolog of Chlamydomonas: two isoforms generated by differential splicing. Plant Cell. 13, 2823-2839

12 Willmund, F., Dorn, K. V., Schulz-Raffelt, M. and Schroda, M. (2008) The Chloroplast DnaJ Homolog CDJ1 of Chlamydomonas reinhardtii Is Part of a Multichaperone Complex Containing HSP70B, CGE1, and HSP90C. Plant Physiol. 148, 2070-2082

13 Schroda, M., Vallon, O., Wollman, F. A. and Beck, C. F. (1999) A chloroplasttargeted heat shock protein 70 (HSP70) contributes to the photoprotection and repair of photosystem II during and after photoinhibition. Plant Cell. 11, 1165-1178

14 Cheetham, M. E. and Caplan, A. J. (1998) Structure, function and evolution of DnaJ: conservation and adaptation of chaperone function. Cell Stress Chaperones. 3, 28-36

15 Heide, H., Nordhues, A., Drepper, F., Nick, S., Schulz-Raffelt, M., Haehnel, W. and Schroda, M. (2009) Application of quantitative immunoprecipitation combined with knockdown and cross-linking to Chlamydomonas reveals the presence of vesicle-inducing protein in plastids 1 in a common complex with chloroplast HSP90C. Proteomics. 9, 30793089

16 Liu, C., Willmund, F., Whitelegge, J. P., Hawat, S., Knapp, B., Lodha, M. and Schroda, M. (2005) J-domain protein CDJ2 and HSP70B are a plastidic chaperone pair that interacts with vesicle-inducing protein in plastids 1 . Mol Biol Cell. 16, 1165-1177

17 Liu, C., Willmund, F., Golecki, J. R., Cacace, S., Hess, B., Markert, C. and Schroda, M. (2007) The chloroplast HSP70B-CDJ2-CGE1 chaperones catalyse assembly and disassembly of VIPP1 oligomers in Chlamydomonas. Plant J. 50, 265-277

18 Harris, E. H. (1989) The Chlamydomonas sourcebook: A comprehensive guide to biology and laboratory use. Academic Press Inc, San Diego, CA

19 Willmund, F. and Schroda, M. (2005) HEAT SHOCK PROTEIN 90C is a bona fide Hsp90 that interacts with plastidic HSP70B in Chlamydomonas reinhardtii. Plant Physiol. 138, 2310-2322

20 Von Kampen, J., Nieländer, U. and von Wettern, M. (1994) Stress-dependent transcription of a gene encoding a Gb-like polypeptide from Chlamydomonas reinhardtii. J Plant Physiol. 143, 756-758

21 Laemmli, U. K. (1970) Cleavage of structural proteins during the assembly of the head of bacteriophage T4. Nature. 227, 680-685

22 Popov, N., Schmitt, S. and Matthies, H. (1975) Eine störungsfreie Mikromethode zur Bestimmung des Proteingehalts in Gewebshomogenaten. Acta Biol Germ. 34, 1441-1446

23 Eriksson, M., Karlsson, J., Ramazanov, Z., Gardestrom, P. and Samuelsson, G. (1996) Discovery of an algal mitochondrial carbonic anhydrase: molecular cloning and 
characterization of a low-CO2-induced polypeptide in Chlamydomonas reinhardtii. Proc Natl Acad Sci U S A. 93, 12031-12034

24 Pierre, Y. and Popot, J. L. (1993) Identification of two 4-kDa miniproteins in the cytochrome $b_{6}$ f complex from Chlamydomonas reinhardtii. C R Acad Sci III. 316, 1404-1409 25 Zerges, W. and Rochaix, J. D. (1998) Low density membranes are associated with RNA-binding proteins and thylakoids in the chloroplast of Chlamydomonas reinhardtii. J Cell Biol. 140, 101-110

26 Eriksson, M., Gardestrom, P. and Samuelsson, G. (1995) Isolation, Purification, and Characterization of Mitochondria from Chlamydomonas reinhardtii. Plant Physiol. 107, 479483

27 Gill, S. C. and von Hippel, P. H. (1989) Calculation of protein extinction coefficients from amino acid sequence data. Anal Biochem. 182, 319-326

28 Willmund, F., Muhlhaus, T., Wojciechowska, M. and Schroda, M. (2007) The $\mathrm{NH}_{2^{-}}$ terminal domain of the chloroplast GrpE homolog CGE1 is required for dimerization and cochaperone function in vivo. J Biol Chem. 282, 11317-11328

29 Asamizu, E., Miura, K., Kucho, K., Inoue, Y., Fukuzawa, H., Ohyama, K., Nakamura, Y. and Tabata, S. (2000) Generation of expressed sequence tags from low-CO2 and high-CO2 adapted cells of Chlamydomonas reinhardtii. DNA Res. 7, 305-307

30 Asamizu, E., Nakamura, Y., Sato, S., Fukuzawa, H. and Tabata, S. (1999) A large scale structural analysis of cDNAs in a unicellular green alga, Chlamydomonas reinhardtii. I. Generation of 3433 non-redundant expressed sequence tags. DNA Res. 6, 369-373

31 Emanuelsson, O., Nielsen, H. and von Heijne, G. (1999) ChloroP, a neural networkbased method for predicting chloroplast transit peptides and their cleavage sites. Protein Sci. 8, 978-984

32 Merchant, S. S., Prochnik, S. E., Vallon, O., Harris, E. H., Karpowicz, S. J., Witman, G. B., Terry, A., Salamov, A., Fritz-Laylin, L. K., Marechal-Drouard, L., Marshall, W. F., Qu, L. H., Nelson, D. R., Sanderfoot, A. A., Spalding, M. H., Kapitonov, V. V., Ren, Q., Ferris, P., Lindquist, E., Shapiro, H., Lucas, S. M., Grimwood, J., Schmutz, J., Cardol, P., Cerutti, H., Chanfreau, G., Chen, C. L., Cognat, V., Croft, M. T., Dent, R., Dutcher, S., Fernandez, E., Fukuzawa, H., Gonzalez-Ballester, D., Gonzalez-Halphen, D., Hallmann, A., Hanikenne, M., Hippler, M., Inwood, W., Jabbari, K., Kalanon, M., Kuras, R., Lefebvre, P. A., Lemaire, S. D., Lobanov, A. V., Lohr, M., Manuell, A., Meier, I., Mets, L., Mittag, M., Mittelmeier, T., Moroney, J. V., Moseley, J., Napoli, C., Nedelcu, A. M., Niyogi, K., Novoselov, S. V., Paulsen, I. T., Pazour, G., Purton, S., Ral, J. P., Riano-Pachon, D. M., Riekhof, W., Rymarquis, L., Schroda, M., Stern, D., Umen, J., Willows, R., Wilson, N., Zimmer, S. L., Allmer, J., Balk, J., Bisova, K., Chen, C. J., Elias, M., Gendler, K., Hauser, C., Lamb, M. R., Ledford, H., Long, J. C., Minagawa, J., Page, M. D., Pan, J., Pootakham, W., Roje, S., Rose, A., Stahlberg, E., Terauchi, A. M., Yang, P., Ball, S., Bowler, C., Dieckmann, C. L., Gladyshev, V. N., Green, P., Jorgensen, R., Mayfield, S., Mueller-Roeber, B., Rajamani, S., Sayre, R. T., Brokstein, P., Dubchak, I., Goodstein, D., Hornick, L., Huang, Y. W., Jhaveri, J., Luo, Y., Martinez, D., Ngau, W. C., Otillar, B., Poliakov, A., Porter, A., Szajkowski, L., Werner, G., Zhou, K., Grigoriev, I. V., Rokhsar, D. S. and Grossman, A. R. (2007) The Chlamydomonas genome reveals the evolution of key animal and plant functions. Science. 318, 245-250

33 Edwards, K. D., Anderson, P. E., Hall, A., Salathia, N. S., Locke, J. C., Lynn, J. R., Straume, M., Smith, J. Q. and Millar, A. J. (2006) FLOWERING LOCUS C mediates natural variation in the high-temperature response of the Arabidopsis circadian clock. Plant Cell. 18, 639-650

34 Usadel, B., Blasing, O. E., Gibon, Y., Retzlaff, K., Hohne, M., Gunther, M. and Stitt, M. (2008) Global transcript levels respond to small changes of the carbon status during 
progressive exhaustion of carbohydrates in Arabidopsis rosettes. Plant Physiol. 146, 18341861

35 Stombaugh, N. A., Sundquist, J. E., Burris, R. H. and Orme-Johnson, W. H. (1976) Oxidation-reduction properties of several low potential iron-sulfur proteins and of methylviologen. Biochemistry. 15, 2633-2641

36 Gibney, B. R., Mulholland, S. E., Rabanal, F. and Dutton, P. L. (1996) Ferredoxin and ferredoxin-heme maquettes. Proc Natl Acad Sci U S A. 93, 15041-15046

37 Weitzmann, A., Baldes, C., Dudek, J. and Zimmermann, R. (2007) The heat shock protein 70 molecular chaperone network in the pancreatic endoplasmic reticulum - a quantitative approach. The FEBS journal. 274, 5175-5187

38 Schwarz, C., Elles, I., Kortmann, J., Piotrowski, M. and Nickelsen, J. (2007) Synthesis of the D2 protein of photosystem II in Chlamydomonas is controlled by a high molecular mass complex containing the RNA stabilization factor Nac2 and the translational activator RBP40. Plant Cell. 19, 3627-3639

39 Nickelsen, J. (2000) Mutations at three different nuclear loci of Chlamydomonas suppress a defect in chloroplast psbD mRNA accumulation. Curr Genet. 37, 136-142

40 Nickelsen, J., Fleischmann, M., Boudreau, E., Rahire, M. and Rochaix, J. D. (1999) Identification of cis-acting RNA leader elements required for chloroplast psbD gene expression in Chlamydomonas. Plant Cell. 11, 957-970

41 Fukuyama, K., Matsubara, H., Tsukihara, T. and Katsube, Y. (1989) Structure of [4Fe4S] ferredoxin from Bacillus thermoproteolyticus refined at 2.3 A resolution. Structural comparisons of bacterial ferredoxins. J Mol Biol. 210, 383-398

42 Beja, O., Koonin, E. V., Aravind, L., Taylor, L. T., Seitz, H., Stein, J. L., Bensen, D. C., Feldman, R. A., Swanson, R. V. and DeLong, E. F. (2002) Comparative genomic analysis of archaeal genotypic variants in a single population and in two different oceanic provinces. Appl Environ Microbiol. 68, 335-345

43 Brochier-Armanet, C., Boussau, B., Gribaldo, S. and Forterre, P. (2008) Mesophilic Crenarchaeota: proposal for a third archaeal phylum, the Thaumarchaeota. Nature reviews. 6, 245-252

44 Lopez-Garcia, P., Brochier, C., Moreira, D. and Rodriguez-Valera, F. (2004) Comparative analysis of a genome fragment of an uncultivated mesopelagic crenarchaeote reveals multiple horizontal gene transfers. Environmental microbiology. 6, 19-34

45 Hoff, K. G., Silberg, J. J. and Vickery, L. E. (2000) Interaction of the iron-sulfur cluster assembly protein IscU with the Hsc66/Hsc20 molecular chaperone system of Escherichia coli. Proc Natl Acad Sci U S A. 97, 7790-7795

46 Kessler, D. and Papenbrock, J. (2005) Iron-sulfur cluster biosynthesis in photosynthetic organisms. Photosynth Res. 86, 391-407

47 Lange, H., Kaut, A., Kispal, G. and Lill, R. (2000) A mitochondrial ferredoxin is essential for biogenesis of cellular iron-sulfur proteins. Proc Natl Acad Sci U S A. 97, 10501055

48 Lill, R. and Muhlenhoff, U. (2005) Iron-sulfur-protein biogenesis in eukaryotes. Trends Biochem Sci. 30, 133-141

49 Godman, J. and Balk, J. (2008) Genome analysis of Chlamydomonas reinhardtii reveals the existence of multiple, compartmentalized iron-sulfur protein assembly machineries of different evolutionary origins. Genetics. 179, 59-68

50 Fukuyama, K. (2004) Structure and function of plant-type ferredoxins. Photosynth Res. 81, 289-301

51 Marín-Navarro, J., Manuell, A., Wu, J. and Mayfield, S. (2007) Chloroplast translation regulation Photosynth Res. 94, 359-374 
52 Alfano, C. and McMacken, R. (1989) Ordered assembly of nucleoprotein structures at the bacteriophage lambda replication origin during the initiation of DNA replication. J Biol Chem. 264, 10699-10708

53 Wickner, S., Hoskins, J. and McKenney, K. (1991) Monomerization of RepA dimers by heat shock proteins activates binding to DNA replication origin. Proc Natl Acad Sci U S A. 88, 7903-7907

54 Kiley, P. J. and Beinert, H. (2003) The role of Fe-S proteins in sensing and regulation in bacteria. Current opinion in microbiology. 6, 181-185

55 Tamura, K., Dudley, J., Nei, M. and Kumar, S. (2007) MEGA4: Molecular Evolutionary Genetics Analysis (MEGA) software version 4.0. Molecular biology and evolution. 24, 1596-1599

56 Emanuelsson, O., Nielsen, H., Brunak, S. and von Heijne, G. (2000) Predicting subcellular localization of proteins based on their N-terminal amino acid sequence. J Mol Biol. 300, 1005-1016 


\section{TABLES AND FIGURES}

Table 1 Properties of the CDJ3-5 proteins

\begin{tabular}{|c|c|c|c|c|c|c|}
\hline Name & $\begin{array}{l}\text { Calculated } \\
M_{\mathrm{r}} \\
\text { precursor } \\
\text { (aa) }\end{array}$ & $\begin{array}{l}\text { Calculated } \\
M_{\mathrm{r}} \\
\text { mature }^{1} \\
\text { (aa) }\end{array}$ & $\begin{array}{c}\text { Apparent } \\
M_{r} \\
\text { in SDS- } \\
\text { PAGE }\end{array}$ & $\begin{array}{c}\% \mathrm{id} / \mathrm{sim} \\
\text { to mature } \\
\text { CDJ3 }\end{array}$ & $\begin{array}{c}\% \text { id } / \mathrm{sim} \\
\text { to } \\
\text { mature } \\
\text { CDJ4 }\end{array}$ & mature \\
\hline CDJ3 & $\begin{array}{c}43111.3 \\
(393)\end{array}$ & $\begin{array}{c}38258.6 \\
(353)\end{array}$ & $\sim 38000$ & & & \\
\hline CDJ4 & $\begin{array}{c}41789.1 \\
(371)\end{array}$ & $\begin{array}{c}33136.2 \\
(306)\end{array}$ & $\sim 34000$ & & & 4.97 \\
\hline CDJ5 & $\begin{array}{c}42851.5 \\
(383)\end{array}$ & $\begin{array}{c}37737.6 \\
(334)\end{array}$ & - & & $5 / 50$ & 5.49 \\
\hline
\end{tabular}

Figure 1 Phylogenetic tree and alignment of CDJ3-5 homologs

(A) Phylogram based on an alignment of the amino acid sequences from CDJ3-5 and their homologs, all lacking the extensions $\mathrm{N}$-terminal from their J-domains. Sequences used were from the following organisms: Oryza sativa (Os1-4, accessions NP_001056124, NP_001044143, EAY98784, and NP_001054247, respectively), Arabidopsis thaliana (AtDjC17 and AtDjC18, accessions NP_197715 and NP_565982, respectively), Vitis vinifera (Vv1-3, accessions CAO69912, CAN73797, and CAO39001, respectively), Picea sitchensis (Ps1-3, accessions ABK21719, ABK24669, and assembly of ESTs DR538561 and ES860441, respectively), Physcomitrella patens (Pp1-3, accessions EDQ75158 [complemented with ESTs FC338026 and FC448519], EDQ53968, and EDQ72847, respectively), Ostreococcus tauri (Ot1, accession CAL50030), and Chlamydomonas reinhardtii (CrCDJ3-5, accessions GQ421467, GQ421467 and EDP07097, respectively). Phylogenetic analysis was conducted using version 4 of the MEGA program [55] on the basis of alignments made by version 1.8 of CLUSTALW. The scale bar indicates 0.1 substitutions per site.

(B) Alignment of amino acid sequences of CDJ3-5 homologs. Sequences were limited to one representative for the CDJ3/4 and CDJ5 clades from angiosperms, gymnosperms, moss, and algae from the same sources as in (A). Included is also the sequence of Synechocystis sp. PCC 6803 bacterial type ferredoxin (accession BAA10759). Amino acids highlighted in black are conserved in all 10 proteins; those highlighted in gray are conserved in at least 8 of them. Italicized sequences represent chloroplast transit peptides as predicted by TargetP [56] or ChloroP [31], with the underlined residue in boldface corresponding to the first amino acid of the mature protein. No prediction was obtained for Pp2. Asterisks indicate cysteines involved in [4Fe-4S] cluster binding [41] and boxed regions represent patches enriched in 
aromatic and charged residues. Alignments were done by CLUSTALW and the GeneDoc program was used for presentation.

Figure $2 C D J 3$ and $C D J 4$ mRNA accumulation after heat shock and dark-to-light shift mRNA from Chlamydomonas wild type cells that were exposed to a heat shock at $40^{\circ} \mathrm{C}$ or that were grown for $16 \mathrm{~h}$ in the dark and then shifted to low light $\left(30 \mu \mathrm{E} \mathrm{m} \mathrm{m}^{-2} \mathrm{~s}^{-1}\right)$ was separated on agarose gels $(10 \mu \mathrm{g}$ per lane) and transferred to nylon membranes. These were hybridized with probes generated from the coding regions of HSP7OB (positive control), $C D J 3, C D J 4$, and CBLP (loading control).

\section{Figure 3 Heterologous expression of CDJ3 and CDJ4}

CDJ3 and CDJ4 were expressed as C-terminal fusions to the Sce VMA intein containing a chitin binding domain, purified by chitin affinity chromatography, and eluted after thiolinduced cleavage of the intein. Aliquots obtained during the purification steps were separated on $10 \%$ SDS-polyacryamide gels and stained with Coomassie Brilliant blue. Lane 1: lysates of $E$. coli host cells after induction with IPTG. Lane 2: supernatant of cell lysates after a 20min centrifugation at $20.000 \mathrm{~g}$. Lane 3: flow-through. Lane 4: $0.5 \%$ of eluate (fraction 4) after thiol-induced cleavage. Lane 5: $0.3 \%$ of fractions $1-3$ \& 5 after concentration. Lane 6: proteins remaining on the chitin column after elution. The positions of the fusion proteins (FP), cleaved CDJ3/4, and of the Saccharomyces cerevisiae VMA intein/chitin binding domain (CBD) are indicated. Pictures of eluted proteins at concentrations of $3 \mu \mathrm{g} / \mu \mathrm{l}(\mathrm{CDJ} 3)$ and $1 \mu \mathrm{g} / \mu \mathrm{l}(\mathrm{CDJ} 4)$.

\section{Figure 4 UV-vis spectra of purified proteins}

(A) The spectra of oxidized (-) and dithionite reduced CDJ3 (...) are shown. The dominant absorbance below $400 \mathrm{~nm}$ in the spectra of the reduced samples derives from dithionite. The inset represents the reduced-minus-oxidized difference spectrum.

(B) Spectra of CDJ4 recorded as described in (A) for CDJ3.

\section{Figure 5 Glutaraldehyde-crosslinking of HSP70B and CDJ3/4}

$0.5 \mu \mathrm{M}$ of purified HSP70B, CDJ3 and CDJ4 were incubated alone or in the combinations indicated for $30 \mathrm{~min}$ at $30^{\circ} \mathrm{C}$ in the presence of $0.5 \mathrm{U}$ apyrase (-ATP) or $200 \mu \mathrm{M}$ ATP (+ATP). Proteins were crosslinked for $15 \mathrm{~min}$ with $0.05 \%$ glutaraldehyde (GA), separated on a $4-18 \%$ SDS-polyacrylamide gel and analyzed by immunoblotting.

\section{Figure 6 Gel filtration of CDJ3 and CDJ4}

$50 \mu \mathrm{g}$ of purified CDJ3 (solid gray line) and CDJ4 (dotted black line) were loaded onto a Superdex 200 gel filtration column and developed at a flow rate of $0.5 \mathrm{ml} / \mathrm{min}$. The calibration curve for thyroglobulin (669 kDa), apoferritin (443 kDa), $\beta$-amylase (200 kDa), BSA (66 kDa), carbonic anhydrase $(29 \mathrm{kDa})$, and cytochrome c $(12.4 \mathrm{kDa})$ is shown in the inset.

\section{Figure 7 Enrichment and subcellular localization of CDJ3/4}

(A) Enrichment of CDJ3/4 from whole-cell extracts. Chlamydomonas whole cells were lysed by sonication in the presence of $2 \%$ Triton X-100 and solubilized material was separated from non-soluble matter by centrifugation through a $0.6 \mathrm{M}$ sucrose cushion. The supernatant was incubated with Sepharose beads coupled to preimmune serum (Pre) or to anti-CDJ3 and anti-CDJ4 antisera. Whole-cell proteins (WC) and precipitated proteins were separated on $7.5-15 \%$ SDS-polyacrylamide gels and analyzed by immunoblotting.

(B) Subcellular localization of CDJ3/4. Chlamydomonas chloroplasts (Cp) were separated into soluble stroma (St), low density membranes (LM), and thylakoid membrane fractions (Th). Mitochondria (Mt) were isolated from the same strain. $7 \mu \mathrm{g}$ proteins of whole cells (WC) 
and subfractions were separated on a $7.5-15 \%$ SDS-polyacrylamide gel and analyzed by immunoblotting with antisera against HSP70B, CDJ3, CDJ4, thylakoidal cytochrome f (Cytf), stromal CGE1, and mitochondrial carbonic anhydrase (CA). Antibodies against CDJ3 and CDJ4 were affinity-purified.

\section{Figure 8 Gel filtration analysis of CDJ3 complexes}

Stromal proteins were separated according to their native size by size exclusion chromatography before being subjected to SDS-PAGE and western analysis using indicated antisera. Analysed protein extracts included wild-type stromal proteins without (WT) and with RNase treatment (WT+RNase) and those from the PRB2A mutant lacking the psbD mRNA (PRB2A). Elution profiles of marker proteins (in $\mathrm{kDa}$ ) are given at the top together with respective fraction numbers.

\section{Supplemental Figure 1 Circadian regulation of Arabidopsis CDJ3-5 homologs}

The log2 scaled mRNA expression levels of AtDjC17 and AtDjC18 in various microarrays pertaining to sugar, light, and cycles are shown. The figure shows from left to right, the response of seedlings to light from the Atgenexpress data set; plants left in the dark compared to the expression after plants were shifted from the dark to the light at compensation point $\mathrm{CO}_{2}$; plants shifted from the dark to the light at compensation point or ambient $\mathrm{CO}_{2}$; the expression of $A t D j C 17$ and $A t D j C 18$ in a seedling culture grown under full nutrition (FN), carbon starvation (-C), and 30 minutes or $3 \mathrm{~h}$ of sucrose re-addition; the expression in seedlings in constant light after entraining a $12 \mathrm{~h} / 12 \mathrm{~h}$ light dark cycle where subjective night phases are indicated by dashed gray lines; the expression throughout the diurnal cycle, where the light and dark phases are indicated by yellow and gray backgrounds, respectively.

\section{Supplemental Figure 2 Alignment of J-domain/bacterial ferredoxin domain proteins from mesophilic crenarchaeota (Thaumarchaeota)}

Sequences used were from the following organisms: uncultured crenarchaeote DeepAntEC39 (Ucr1, accession AAR24498), uncultured marine crenarchaeote AD1000-207-H3 (Ucr2, accession ACF09820), uncultured marine crenarchaeote AD1000-56-E4 (Ucr3, accession ACF09658), uncultured crenarchaeote 74A4 (Ucr4, accession AAK96090), Nitrosopumilus maritimus SCM1 (Nm1, accession YP_001582358), and Cenarchaeum symbiosum A, (CsA, accession YP_875357). Amino acids highlighted in black are conserved in all 6 proteins; those highlighted in gray are conserved in at least 5 of them. Asterisks indicate cysteines involved in [4Fe-4S] cluster binding and boxed regions represent patches enriched in aromatic and charged residues. 


\section{Figure 1}

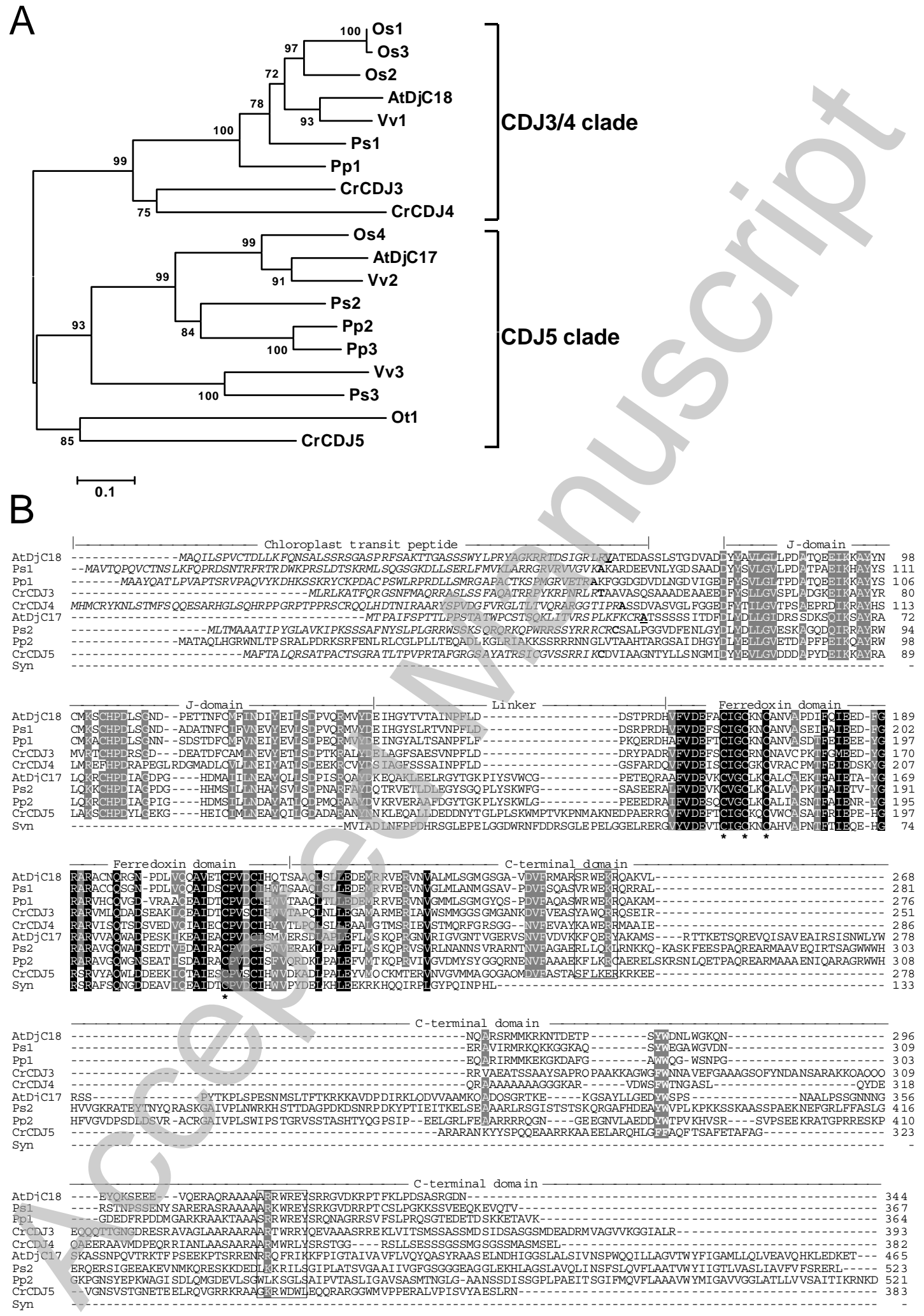

Licenced copy. Copying is not permitted, except with prior permission and as allowed by law. (C) 2010 The Authors Journal compilation (c) 2010 Portland Press Limited 
Biochemical Journal Immediate Publication. Published on 29 Jan 2010 as manuscript BJ20091412

Figure 2

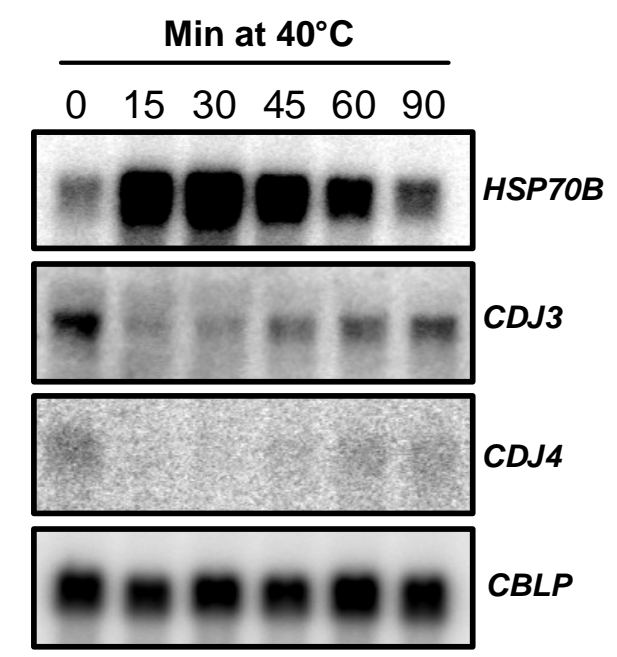

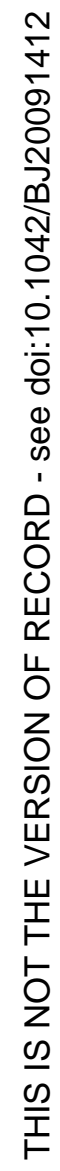

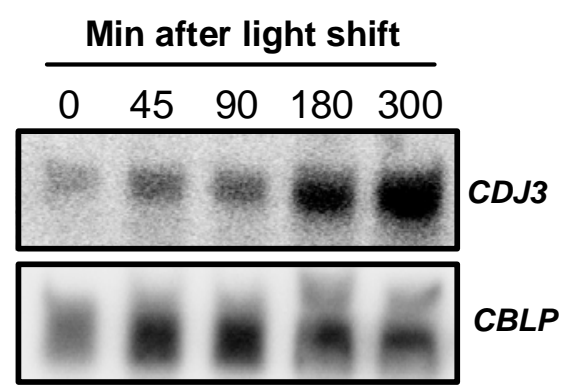

Figure 3
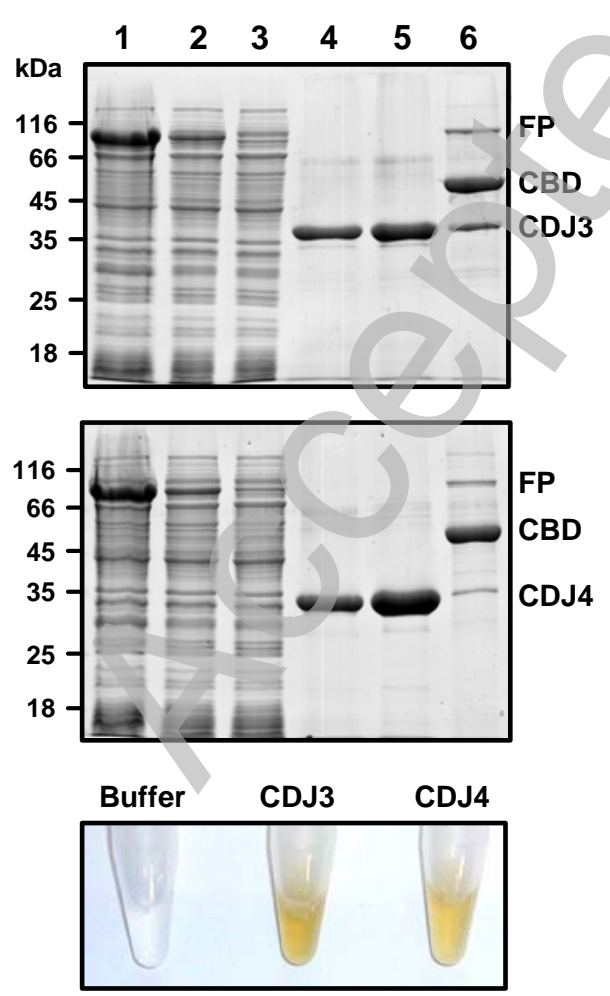

Licenced copy. Copying is not permitted, except with prior permission and as allowed by law. (C) 2010 The Authors Journal compilation (c) 2010 Portland Press Limited 
Biochemical Journal Immediate Publication. Published on 29 Jan 2010 as manuscript BJ20091412

Figure 4

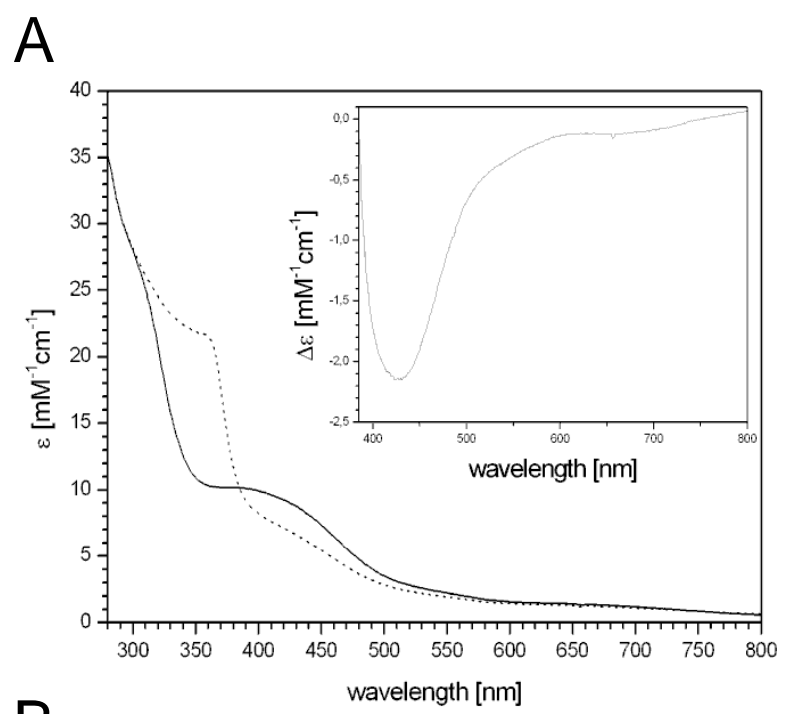

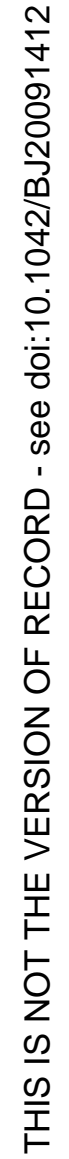

B

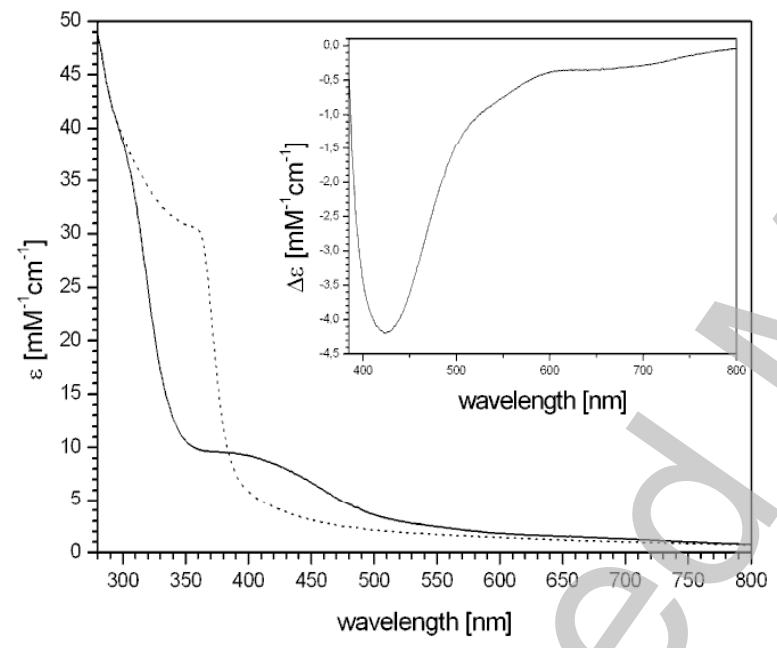

Figure 5

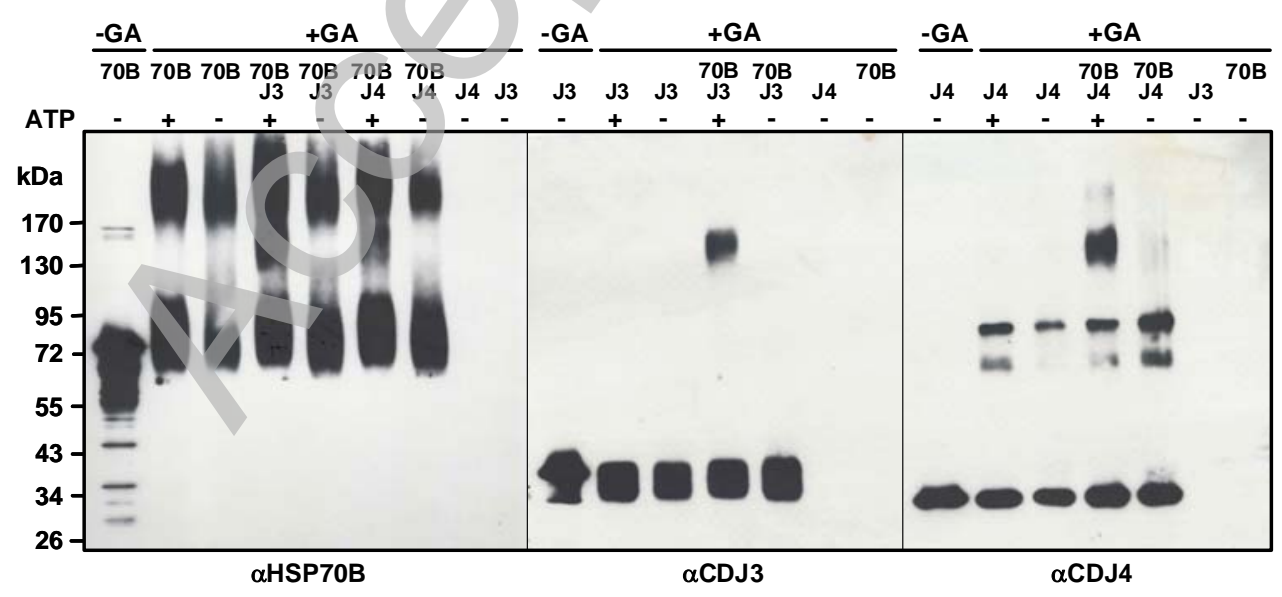

Licenced copy. Copying is not permitted, except with prior permission and as allowed by law. (C) 2010 The Authors Journal compilation (c) 2010 Portland Press Limited 


\section{Figure 6}

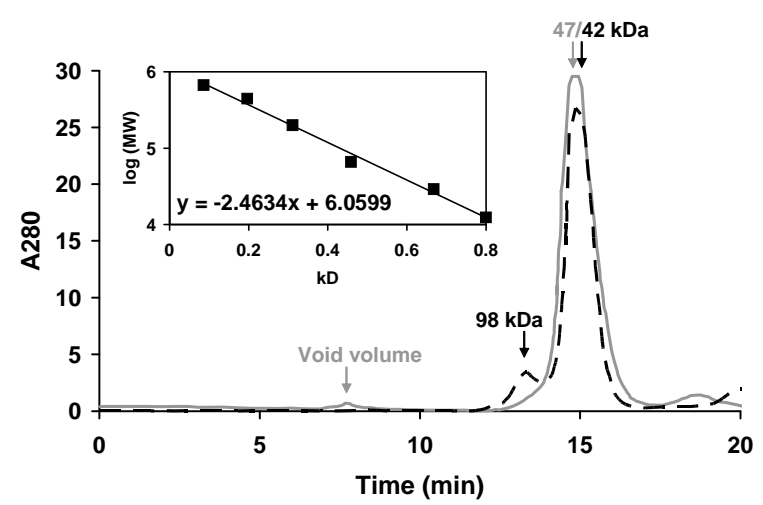

Figure 7
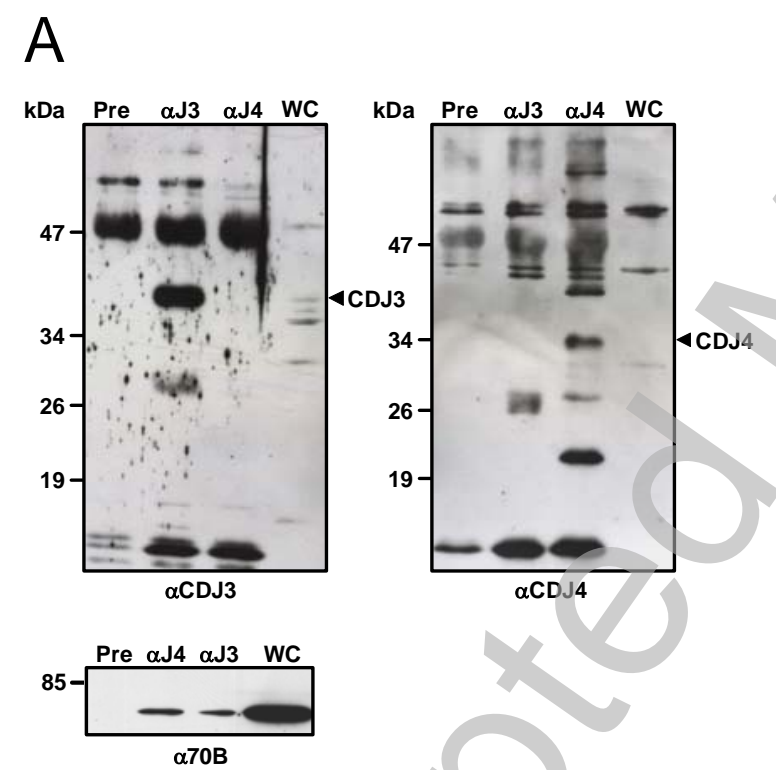

B

WC Cp St LM Th Mt

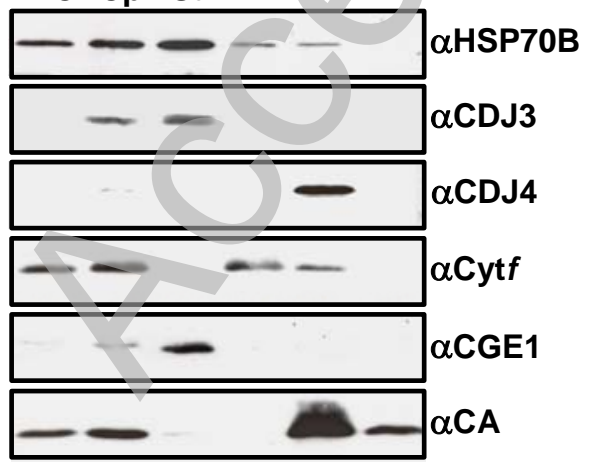


Figure 8

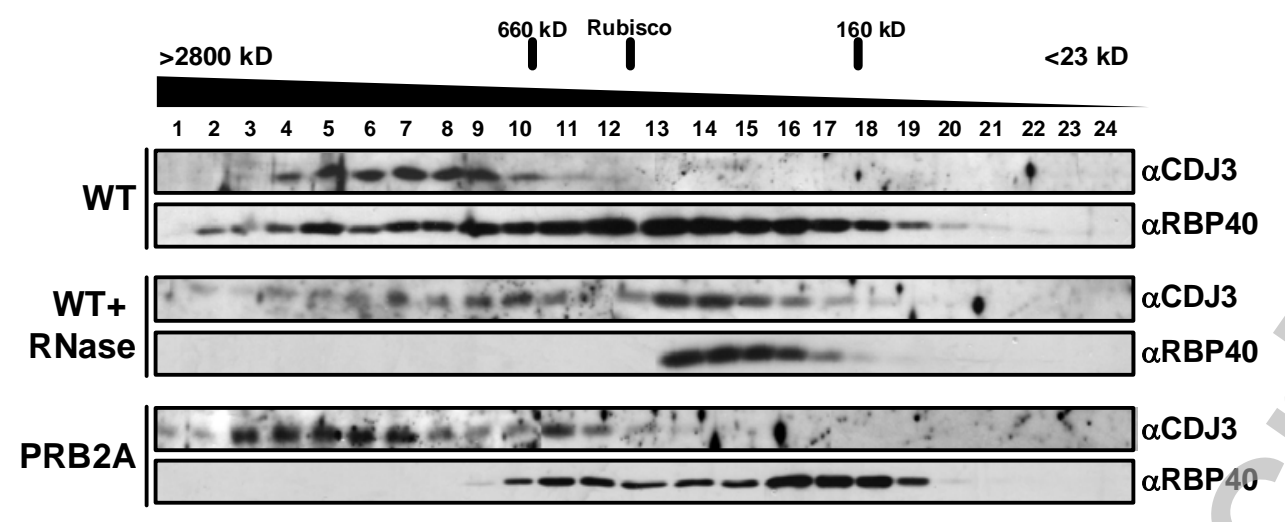

